ISBN: 978-84-1311-213-8 (pdf)

DOI: https://dx.doi.org/10.14201/0AQ02846162

\title{
Taller Abierto
}

\author{
Jesús Alonso Alonso
}

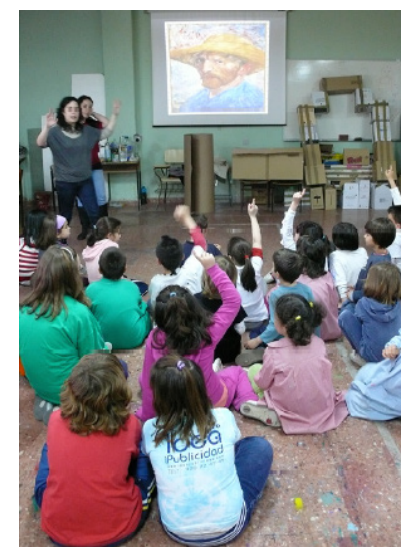

T A NECESIDAd DE QUe los ESTUdiANTES del Grado de Maestro conozcan de manera experimental los recursos y comportamientos de los niños en el ámbito de la actividad $\checkmark$ artística, hace que se plantee este Proyecto.

Los objetivos que se persiguen son:

- Completar la formación de los futuros maestros en el ámbito de la educación artística desde la práctica y en un entorno de realidad profesional tutorizada.

- Los niños participantes acceden a experiencias de taller ausentes en su entorno educativo.

- Constituir un cuerpo de trabajos necesarios para la formación de un museo de arte infantil.

Este proyecto se implanta en la asignatura Optativa «Dibujo artístico y su didáctica» ofrecida a los estudiantes de Grado de las especialidades de Maestro de Educación Infantil y Maestros de Educación Primaria en la Escuela Universitaria de Educación y Turismo de Ávila.

En cuanto al servicio que se presta a la comunidad, los/as niños/as participantes tienen unas experiencias que no les ofrece ni la escuela ni la familia; conocen un modelo de educación artística que desarrolla y potencia su identidad. 
Si nos centramos en el aprendizaje, el Taller Abierto completa la formación de los futuros maestros en el ámbito de la educación artística desde la práctica.

Los estudiantes universitarios maduran personal y profesionalmente gracias a las diferentes responsabilidades que deben asumir en el desarrollo del taller, ya que deben diseñar acciones similares a la que será su futura realidad profesional.

El taller se estructura de la siguiente forma:

a) Dos horas semanales entre estudiantes y profesor para:

i. Revisar la anterior sesión del taller.

ii. Preparar la sesión sucesiva a partir de los conocimientos previos de los que disponen los estudiantes.

b) Dos horas semanales para realizar el taller con los/as niños/ as:

i. Los estudiantes llevan a cabo el taller con los niños.

El proyecto supone una convocatoria libre y gratuita para niños de 3 a 12 años.

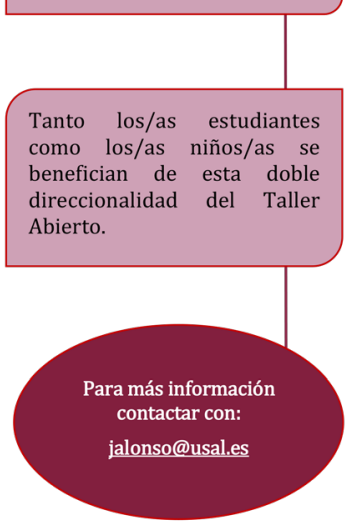

ii. Cada estudiante dirige una de las actividades y el resto sirven como auxiliares. iii. El profesor toma un papel de coordinador para la óptima fluidez del taller.

En cuanto a los resultados, destaca:

- El estudiante se autopercibe como el centro del proceso enseñanza-aprendizaje.

- Adquieren destrezas para el diseño de situaciones similares a la futura realidad profesional.

- La experiencia directa constituye aprendizaje/conocimiento.

- Los/as niños/as tienen unas experiencias nuevas con materiales y procesos artísticos.

La mayor innovación de la experiencia Taller Abierto es que implica todas las facetas del individuo (conocimientos, estrategias y destrezas comunicativas y afectivas, elaboración de materiales didácticos, aprendizaje de la realidad y no solo de los textos académicos, etc.), lidiando así con la transmisión activa de conocimientos y experiencias por parte del estudiante.

Este carácter innovador reside en confrontar al estudiante con situaciones similares al mundo profesional, pero en un entorno de bajo riesgo.

Para divulgar la inscripción en el taller se han utilizado los propios colegios de Ávila, carteles en los centros, diferentes medios de comunicación, etc.

Del mismo modo, para dar a conocer la práctica se ha participado en diferentes Jornadas. 